Acta Poetica 25-1

PRIMAVERA

2004

\title{
Tostador traducido
}

\section{Francisco Hinojosa}

Malas noticias para los traductores: su oficio se está extinguiendo. Con los actuales programas de computadora para traducción, muy pronto las editoriales de todo el mundo se verán libres de tratar con esos seres engorrosos. Un simple botón de la computadora resolverá en cosa de minutos o hasta segundos el trabajo que hoy día se lleva meses y hasta años de penoso esfuerzo. Tomando como ejemplo el manual de instrucciones de un tostador, Francisco Hinojosa, escritor mexicano, nos muestra el adelanto extraordinario que han tenido estos programas.

Bad news for translators: their work is becoming extinct. With the existing programs for computerized translation, editing companies will get rid of these annoying beings. The simple pressing of one key will accomplish in minutes, even seconds, the task that today takes months, even years. Using the instructions manual for a bread toaster as an example, Francisco Hinojosa, Mexican writer, shows us the extraordinary improvement these programs have attained. 


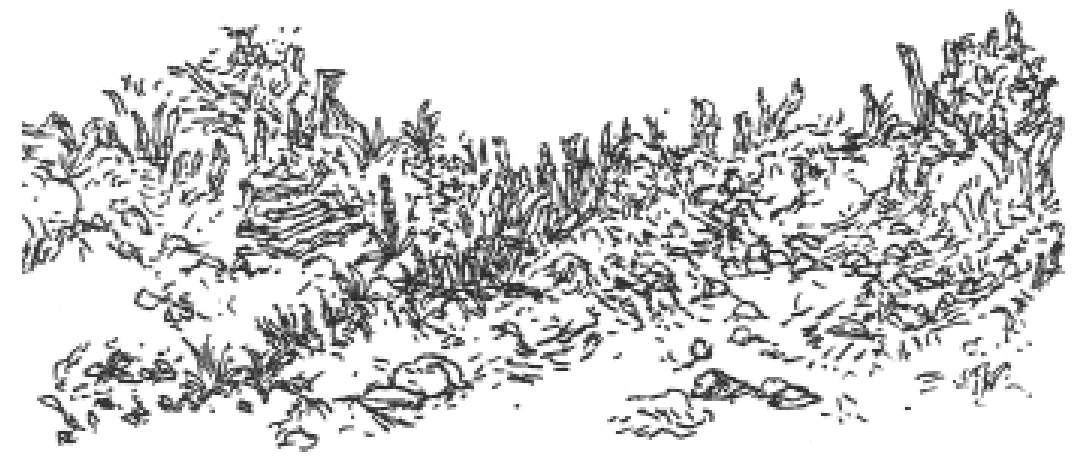


Acta Poetica 25-1

PRIMAVERA

2004

Francisco Hinojosa

\section{Tostador traducido}

Tener un tostador de pan puede significar muchas cosas: entre otras, una mañana agradable de café con pan caliente untado con crema de cacahuate y mermelada de zarzamora.

Junto al microondas, la lavadora de ropa o el extractor de jugos, el tostador no pasa de ser un aparato que no requiere mayor ciencia que la intuición para entender su rudimentario funcionamiento.

Sin embargo, tener un tostador de pan puede también significar una gran cantidad de dificultades ontológicas (propias del ser) y ontoylógicas (del on'toy). Especialmente si el tostador es de la marca Hamilton Beach (R) y quien lo adquiere decide leer las instrucciones que lo acompañan en vez de guiarse por la intuición.

Los fabricantes de "Hamilton Beach (R) Dos Rebanada Tostador", que no tuvieron tiempo de leer las Historias de cronopios y de famas de Cortázar, se dieron a la tarea de traducir por sus pistolas algo más que unas simples y vulgares instrucciones: un tratado sobre el arte de enseñar al usuario del producto a tostar dos complicadísimas rebanadas de pan.

El punto uno del manual es tan inobjetable como suicida: "Lea todas las instrucciones". El nueve tiene cierto sentido 
("No use fuera de la casa"), pese a que no puede descartarse el caso de quienes gozan de usar su tostador en el granero, la alberca o el motel.

Los problemas (metafísicos, ontológicos, ontoylógicos y lingüísticos) surgen en los demás puntos. El once dice: "No sitio puesto o próximo un caliente gasolina o eléctrico que mador, o en un acalorado horno". Sic. Eso dice, literalmente, la guía de uso del aparato.

Más adelante, dentro del apartado "Guarde estas instrucciones", los fabricantes nos sugieren: "Si normal para su tostador para producto mucho obscuro tostada puesto el obscuro ambiente y mucho claro tostada puesto el claro ambiente, y el ancho alcance entre obscuro y claro voluntad normal traje su necesidad". He tratado de poner en práctica todas las enseñanzas de mi maestro de filología, don Juan M. Lope Blanch, para analizar la estructura sintáctica de esta simple instrucción. $\mathrm{O}$ sus lecciones fueron insuficientes o mi aprendizaje, después de dos exámenes extraordinarios, no alcanzó el grado de pureza de la lengua propuesto por los señores Hamilton Beach.

El punto catorce dicta: "No tentativa o desalojar alimento cuando tostador atarugar en". Y, para terminar, el diecisiete: "No uso toda otro artifico en o mismo eléctrico receptáculo o toda otro receptáculo por o mismo circuito para tostador o él voluntad sobrecarga o circuito o golpe un mecha o circuito cachón".

Afortunadamente la compañía Hamilton Beach (R) no nos instruye acerca de cómo untarle al pan la crema de cacahuate y la mermelada de zarzamora. De seguro la operación sería más complicada que hacerle la afinación y el servicio a un submarino finlandés o una cirugía a corazón abierto a un abulón. Por fortuna, también, la empresa de marras se dedica a fabricar tostadores y no a la enseñanza de la gramática castellana o a la formación de traductores. 
¿Cómo llegó la Hamilton Beach (R) a redactar esta "guía" que el usuario debe acatar para hacer un uso razonable del producto que les da (a los señores Hamilton y/o Beach) para sus bisteces? Propongo las siguientes respuestas: 1) los dueños son oriundos de Sierra Leona, de madre portuguesa y padre mixe, que hablan una combinación de croata con vasco y chocholteco; 2) tienen en su computadora un programa que traduce de su lengua (si la tienen) a una nueva; 3) son tatarancestros de los arquitectos de Babel; 4) sus desayunos nada tienen que ver con el pan tostado, la crema de cacahuate y la mermelada de zarzamora, y 5) suelen utilizar los mingitorios según las instrucciones de uso.

Las autoridades mexicanas (Hacienda, Comercio, Gobernación, Educación Pública, Relaciones Exteriores) otorgaron de seguro su palomita a los importadores Hamilton Beach (R) porque cumplieron con el requisito de adjuntar al aparato tostador las "instrucciones" reglamentarias. Importa poco si los connacionales que adquieran el "producto" terminen por desaprender lo poco que saben de español o lo utilicen según las instrucciones. Tampoco tiene la menor importancia si "un incendio pueden ocurrir si tostador cubierto o conmovedor inflamable material, incluso cortinas, colgaduras, muro, et cetera, cuando en operación".

No tendría el caso mayor importancia si no fuera porque la lengua (esa cosa que usamos para entendernos) puede extraviarse en las decisiones corporativas de los genios anglohablantes de las finanzas, que nos enseñen a tostar un pan o a no meter la mano en la licuadora "cuando en operación". Agradecemos, por supuesto, sus dádivas: sus leyes y las nuestras nos protegen del mal uso de un "circuito cachón".

¿Será que nuestros vecinos del norte saben tanto español que se han impuesto la histórica tarea de enseñarnos a hablarlo y a escribirlo? ¿O será acaso que quieren "instruirnos" — como las normas del comercio lo imponen- acerca de cómo usar sus aparatos? 
Ya existen antecedentes culturales: un día los gringos decidieron que los verdaderos platillos mexicanos son los nachos, las fajitas y los burritos. Decidieron también que el holiday mexicano se celebrara el 5 de mayo, fecha histórica que nada le reclama a los yankis, sino a los franceses. Optaron por certificarnos (o no) como país de narcotránsito, sin detenerse a pensar que son país de narcotráfico. Etcétera: somos los mexicanos (para ellos) lo que su congreso, su comercio y su modo de vida quieren que seamos. Incluso, un país sin lengua propia.

Llegará el día en que los voladores de Wisconsin sean más atractivos que los de Papantla, que un mariachi de Seatle llegue a la dodecafonía y que el mole negro de Oaxaca esté patentado por una corporación texana. Llegará el día en el que Pedro Páramo sea una obra apreciada gracias a los genios de Hollywood o a la mercadotecnia de los empresarios de Broadway. 